\title{
Enhancing Technical Vocabulary Through Morphological Analysis Instruction For Biology-majored Students
}

Kent-David Juen ${ }^{1}$ and Nhon Dang ${ }^{1, *}$

${ }^{1}$ School of Humanities \& Languages, Tan Tao University, Duc Hoa, Long An, 850000, Viet Nam.

ABSTRACT This paper aims to investigate the effectiveness of morphological analysis instruction on grade ten biology-major students in Tan Tao High School for the Gifted in Long An, Vietnam, and to find out whether they can catch up with the level of biotechnology students in Tan Tao University, in terms of science vocabulary performance. The instruction selectively targeted technical multisyllabic words that occur frequently in the participants' corpus. Thirty-one students including eighteen grade-ten biology students as the experimental group and thirteen biotechnology students as the control group participated in the study. For data collection, pre-posttest was designed, validated and applied for the experimental and control group. Apart from the regular teaching method, the experimental group also received explicit morphemic analysis instruction, while the control group only received their regular teaching. Pretest to posttest results revealed that each group registered an increase in the respective means, however, the experimental group surpassed the control group up to 5.9 mean difference. Morphemic analysis confirms its effectiveness in boosting the students' vocabulary acquisition of multisyllabic terminologies that facilitates their learning. The paper ended with some pedagogical implications for teaching technical terms.
KEYWORDS

Technical vocabulary

Biotechnology

Multisyllabic

Acquisition

Performance

Morphological analysis

\section{ARTICLE HISTORY}

Received: 15.08 .2020

Accepted: 01.09.2020

Online: 10.09 .2020

DOI: https://doi.org/10.53901/ekiz5xm074I

\section{INTRODUCTION}

Educating students on how to identify thematic patterns of science to communicate meaning is the mission of science educators [1]. Today's subject-area teachers are encouraged to highlight literacy skills that are tailored to their respective field of study [2] for the purpose of developing students' abilities to read, write, and speak as disciplinary apprentice [3]. Undoubtedly, vocabulary plays a vital role in language learning. Without the adequate knowledge of the technical vocabulary in science, students cannot communicate and express what they learned practically during laboratory exercises and experiments. Although each field of discipline has its own specific vocabulary requirements, the intricacy of science vocabulary, majority derived from Greek and Latin roots [4] [5], generally introduces significant barriers to student learning. As

Dedicated the 10th Anniversary of Tan Tao University it happens, Wellington and Osborne (2001) wrote that the "language of science, rather than the content, is a major barrier to most pupils in learning science" (p.2). A promising approach to learning words that can be adapted to any content area is morphological instruction [6] [7] [8] [9]. In this linguistic strategy, students are taught how to structure words by dissecting the morphemes (i.e., the smallest meaningful unit of a word) to help them spell, comprehend and acquire technical words they encounter while reading content-area written work. An efficient way to enhance students' decoding, spelling, reading comprehension and vocabulary skills is by concentrating morphological instruction [6] [7] [8].

\section{Problem Statement and Context}

Unlike other isolated languages such as Chinese and Thai, Vietnamese is written in extended Latin characters [10], however, words in Vietnamese are often monosyllabic [11]. The monosyllabic- 
ity of the Vietnamese language could be a challenging factor for Vietnamese students to learn multisyllabic words in English. In Vietnam, like many other countries, discipline-specific class discussion is completely dominated by syllabic-based approach where students are taught to utter each syllable of a multimorphemic word. For instance, phagocytosis has 5 syllables, 12 letters, and three morphemes (pronounced as pha-go-cy-to-sis). This strategy helps struggling adolescent readers to decode complex words [12], however, this approach is less effective for students in accessing spelling patterns or the meaning of a word [13]. The fact that syllabic-based approach focuses on the correct utterance of each phoneme in a syllable of a word, it is only effective to students at an early age with reading difficulties [14]. Alternatively, students can parse and analyze parts of the words into meaningful and pronounceable fragments through morphemic analysis (i.e., phago-cyt-osis). This dissecting-strategy supports decoding and provides clues for identifying and memorizing the exact meaning of the word. Phago- derived from Greek that means "to eat", cyte indicating a cell, and - osis denoting a process (i.e., phagocytosis means a process by which certain living cells called phagocytes ingest or engulf other cells or particles). Multi-morphemic science words can be thoroughly examined and employed using morphological instruction to support the recognition of familiar spelling patterns for students to improve their comprehension [15]. Another noticeable issue in discipline-specific fields is that Universities tend to reward research fame which forces professors to spend the vast majority of their time on laboratory research and less emphasis on effective teaching [16]. The common result is that neither the objectives nor the content of courses in the curriculum is concerned with the acquisition of technical vocabulary. Moreover, these technical words of science are transmitted directly without further dissecting and explaining its meaningful fragments. This approach is very similar to communicative language teaching where it has fewer concerns on word structure [17], technical vocabularies and academic words related to science as the target specialized language, channeled instantly to students to produce meaningful communication. Therefore, students of science are not having the opportunity to benefit the pedagogical advantages of morphemic analysis which could potentially enhance their learning on technical words of science.

\section{Questions and Assumptions}

This study attempted to investigate the impact of explicit morphological analysis instruction on developing biology-majored students' spelling and vocabulary performance at Tan Tao High School for the Gifted. Particularly, it sought to answer the following questions.

1. What challenges do biology students in Vietnam face when they acquire technical vocabulary?

2. s there any improvement in students' vocabulary performance if morphological analysis instructions are used?

\section{This study has the following assumptions:}

1. There is a significant difference between the control group and the experimental group in the pretest because naturally, biotechnology students are ahead and more exposed to technical terms compared to the grade ten high school students.

2. There is no significant relationship between the vocabulary performance of the experimental group and the respondents' profile: (a)age; (b)gender
3. There is a significant difference between the control group and the experimental group in pretest.

4. There is a significant difference between the pre/post test of the experimental group.

\section{LITERATURE REVIEW}

The use of morphological instruction has been studied extensively in research. Badawi [17] designed a two-unit explicit morphology instruction program (EMIP), a morphological awareness test (MAT) and a reading comprehension test (RCT) to investigate its effect on developing secondary students' EFL morphological awareness and reading comprehension. The explicit morphology instruction targeted two morphological skills namely, inflectional and derivational skills which basically applies to the majority of English words. Carlisle and Stone [15], through a morphological approach, looked into decoding and familiarizing spelling patterns of multimorphemic science words will be convenient for students' learning. Furthermore, Berninger et al., [11] suggested that students can easily acquire the meaning of complex science words if they recognize these morphemic patterns. Identifying and selecting morphemes are necessary for effective instruction. Zoski, Nellenbach and Erickson [13] emphasized the need for vocabulary selection before instructing morphemic analysis to the target students; the content should include both discipline-specific words and general academic words related to science, also, the vocabularies should be linked to the core concepts of the curriculum so that students will encounter complex words during class lessons promoting high-utility science morpheme. Fang [4] addressed an additional challenge which is the frequent use of nominalization of technical vocabulary that transforms an adjective or verb into a noun. For example, the verb amplify can be transformed into a noun by adding the suffix -ication, resulting in amplification. This affixation may confuse students because suffixes like -ication do not provide any meaning-based information [13]. However, Bowers, Kirby, Deacon, [6] believe that these challenges can be addressed and solved through calculated, well-planned instruction. "Morphological analysis which means breaking an unfamiliar word into parts and then recombining them into a meaningful whole is believed to help students to discover many new words and to use it." [18]. Nevertheless, morphological analysis is ineffective if the students lack the knowledge of the root words and affixes [19]. For that reason, morphological instruction is essential in language literacy programs [20]. Objectively, Manyak, James and Manyak [21] quote Carlise's discovery about the four different objectives in research intervention applying morphological analysis: "(1) awareness of the morphological structure of words; (2) meanings of specific affixes and roots; (3) analysis of how a word's morphemes contribute to its meaning, grammatical function, or spelling; and (4) strategies for using morphological analysis to infer word meanings."(p.2). Although, our pre-posttest was designed to encapsulate these four objectives, it concentrates on selective morphemes that the students encounter in their science texts and class discussion, in other words, the researchers deliberately linked the technical vocabularies and related-academic terms to the content of the school's curriculum. Luong Ha [22] discuss the comparison between English and Vietnamese morpheme system. Firstly, using the affixation. In Vietnamese, an affix can be added to a certain morpheme but the new word will consist of at least two unattached words, unlike in English that when an affix is added it is still in a form of a single word. For instance, the word 'quên' means forget in English, and the by attaching a suffix 'quên lãng' is 
equivalent to the adjective forgetful. Secondly, the tonal alterations in Vietnamese. Vietnamese is commonly described as having six tones, tonal ablaut are used grammatically, but it is not the case in English. This leads to a big difference when forming reduplicants, for example, vàng (yellow) can be formed as vàng vàng (yellowish).

\section{METHODOLOGY}

\section{Research Design}

The study used an experimental and control group design where the participants are allocated to two different groups. This design will reveal the science vocabulary and spelling performance of the experimental group exposed to a given morphological awareness instruction, compared to the control group which will not be given an intervening variable except their usual classroom discussion, which the instructor is using a direct syllabic-based approach. Although the control group is academically advanced compared to the experimental group, the testing results after the intervention will be used to assess whether there is a significant difference between the performance of the two groups. Moreover, this study is mainly quantitative because it includes the scores of the experimental and control groups in the pretest and posttest. And these test results will correlate with their profile.

\section{Participants}

The participants of this study were (18) grade ten students specializing in biology and (13) biotechnology students from Tan Tao University and High School, Vietnam, conducted in October 2019. The participants were separated into two classes. The first class $(n=14)$ which consisted of grade ten students were selected as the experimental group, the remaining biotechnology participants $(n=11)$ represented the control group. Morphemic analysis was taught explicitly on the experimental group in addition to their regular class discussion, the control group only received their regular class discussion where the instructor merely uses a syllabic-based approach. The respondents in the control group have already taken major courses in biotechnology such as, BT_AB101: Introduction to biotechnology and BT_AB102: Cell biology. Meanwhile, the grade 10 students were currently investigating the structure and functions in living organisms.

\section{Semi-Interview Structure Interview}

For qualitative data, the researcher conducted semi-structured interview to each five grade-ten biology-majored students and eight biotechnology students primarily about their preference on laboratory practices or theoretical discussions in the class, and which of these two they like the most. List of questions were prepared (see Appendix E) but the researcher allowed the interviewees to bring new ideas during the interview to further expand and elaborate their concerns and attitude towards the questions given to them.

\section{The intervention applied to experimental group}

During the intervention, the topic of the biology class was narrowed down and the experimental group was taught only about Cell, its organelles and their mechanisms to avoid information glut that may confuse the students. The topic of Cell was chosen because it serves as the basic building blocks of organisms. And by that, it is important to provide the grade 10 students basic inputs about the smallest unit of a living thing. Initially, the explicit instruction of morpheme analysis was applied in a much more general concept. Morpheme segmentation was used and displayed to students to identify the difference between Eukaryotic



Figure 1 Dissecting the meaning of Phospholipid bilayer and its parts using morpheme segmentation [Source: https://www.quora. $\mathrm{com} /$ What-is-the-definition-of-phospholipid-bilayer]

and Prokaryotic Cells, the prefix Eu-derived from Greek which means "good", and the prefix Pro - derived as well from Greek which means "before". And the suffix -karyotic which both words have simply means "kernel" in Greek. The instructor intendedly taught prokaryotic as "good" or better cell in the sense that it has more organelles compared Prokaryotic cells, while the latter type of cell largely dominated by bacterias which can be harmful, so the term was introduced to the students similar to "before" the good, as what the corresponding prefix suggests. After explaining the differences of cell types, the researcher began to explain the organelles through morpheme dissection. For instance, phospholipid bilayer is segmented into 4 parts, 1. phospho- representing phosphorus, 2. lipid- organic acid fatty compounds, 3 . The prefix bi - pertaining to "having two", 4. Layer - arranged in layers (Fig. 1). Then the full meaning is introduced, a two-layered arrangement of phosphate and lipid molecules that form a cell membrane. Through morpheme analysis, it is much easier to explain scientific terms to students by explaining each meaningful unit and combining their meaning afterwards. For instance, Extra- a prefix meaning "outside", cellular - an adjective relating to cell. Therefore, extracellular can be explained as "outside of the cell". Another example, Hydro - a prefix meaning water, phobic - an adjective involving "fear or afraid of", there hydrophobic can be described as "afraid or intolerant of water". The picture above is just one of the illustrations the researcher used to introduce morpheme analysis to the respondents of the experimental group.

\section{Research instrument}

This study will use a researcher pretest- posttest science vocabulary and spelling assessment. This pre-posttest science vocabulary and spelling has three parts: 1.) multiple choice; 2.) fill in the blanks; 3.) spelling exercise where the researcher will dictate a word and the respondents will be asked to spell the word in written form. To avoid information glut that may confuse the respondents, the scope of this test will be limited to the topic about Molecular and Cellular biology. Other useful medical terms and morphemes will not be taught to limit the extent of the test. Part 1 will be a science vocabulary test which is also a multiple-choice test where the respondents will be asked to encircle the letter that corresponds to the meaning. This part has 20 items and each number has four choices. The respondents will be asked to encircle the letter which they think has the correct answer. Part 2 will be fill-in-the-blanks. The students will be asked to complete a statement by adding 
information to a space that has left empty for them to fill their answers which they think is correct. This will be 10 items. Part 3 will be another spelling test where the researcher will dictate a multisyllabic scientific word and the respondents will be asked to spell the word in written form. There will be 10 items in this part.

\section{Data gathering procedure}

This research examines whether the grade ten students specializing in biology can keep pace with the biotechnology students in terms of vocabulary performance. And thus, a section biology in grade ten which composed of eighteen respondents was selected as the experimental group, and thirteen volunteers from biotechnology were selected as the control group where they will not receive any explicit morphology instruction like the first group. These two groups will be subjected to pre-test and post-test procedure. The scores from the pre-test and post-test will be collected and will be recorded by the researcher. The data gathering was done during the month of May to June 2020

\section{Statistical data analysis}

The gathered data will be classified, counted and organized for quantitative analysis. Descriptive statistics will be used in this research such as mean, frequency and percentage. Inferential Statistics will also be used such as independent samples t-test, Spearman rho and Pearson correlation coefficient to determine the relationship and significant difference between the means of two groups. For the first question, mean, frequency count, and percentage will be used to determine the number and percentage of respondents' profile in terms of gender and age. For the second question, the mean difference from the pretest to the posttest of each of the two groups was collected to determine the science vocabulary performance of both experimental and control groups. For the third question, $\mathrm{t}$-test was used to determine the vocabulary level of the control and experimental group. This statistical tool will be used to assess if there is significant difference in the vocabulary level by analyzing the pretest results. The researcher will use SPSS version 26 and Microsoft Excel 2016 to accurately analyze the data.

\section{RESULTS AND DISCUSSION}

Respondents profile in terms of the following: (a) age; (b) gender Along age, one can infer that the respondents of the control and experimental group have a considerable age gap up to $4-5$ years. The highest number of respondents were 16-year-olds.

Table 1 Distribution of respondents in the control and experimental group according to age.

\begin{tabular}{ccc|ccc}
\hline & \multicolumn{3}{c}{ Control Group } & \multicolumn{3}{c}{ Experimental Group } \\
\hline Age & Frequency & Percentage & Age & Frequency & Percentage \\
\hline 19 & 6 & 46.15 & 15 & 7 & 38.89 \\
20 & 7 & 53.85 & 16 & 11 & 61.11 \\
Total & 13 & 100 & Total & 18 & 100 \\
\hline
\end{tabular}

Meanwhile, results have revealed that more than half of the respondents of the control and experimental groups were female. Table 2 shows the distribution of the respondents in the control and experimental group according to gender.

The experimental group has $9.4 \%$ female respondents than the female respondents of the control group while the latter also has
Table 2 Distribution of respondents in Control and Experimental group according to gender.

\begin{tabular}{lcc|cc}
\hline & \multicolumn{2}{c|}{ Control Group } & \multicolumn{2}{c}{ Experimental Group } \\
\hline Gender & Frequency & Percentage & Frequency & Percentage \\
\hline Male & 7 & 53.85 & 8 & 44.44 \\
Female & 6 & 46.15 & 10 & 55.56 \\
Total & 13 & 100 & 18 & 100 \\
\hline
\end{tabular}

9.4\% more male respondents than the male respondents of the experimental group. And thus, along gender, one can infer again that the uncontrolled and controlled group are similar.

\section{What challenges do biology students in Vietnam face when ac- quiring technical vocabulary?}

Preference for Laboratory practices over theoretical discussion For the semi-structured interview, four out of five grade ten biologymajored students chose laboratory experiments over class discussion. Because they find scientific demonstrations and investigations more exhilarating compared to classroom discussion. As one student named Hng describes it "I can absorb and remember the knowledge more practically through experiments". Meanwhile, all eight biotechnology students chose laboratory practice over theoretical discussion in the classroom. Similarly, their answers are related to "directly experimenting the topic is far more interesting". The importance of theoretical discussion is often neglected by biology-majored students because it provides less excitement compared to their actual laboratory experiments, where they can work with the equipment, apparatus, sample tissue, cells, fungus and even microbes in a closed and controlled environment. Forgetting the fact that classroom discussion can also be exciting because it provides a setting where both instructors and students share views on a specific topic that develops students' vocabulary and speaking skills. The monosyllabicity of the Vietnamese Language provides challenges in remembering and pronouncing multisyllabic science words Interestingly, all the respondents of the semi-structured interview have mentioned the monosyllabicity of their mother tongue poses great obstacles for them to comprehend and acquire multisyllabic technical terminologies. According to one of the interviewees named Tun," because our native language is purely monolingual by nature, uttering multisyllabic science words is very difficult and thus, it's also very hard to remember them. For instance, the word DNA translation means DNA dch in Vietnamese, we're not so used to pronouncing these long terms". Khang, also one of the interviewees said "multisyllabic science terms are the complete opposite of the Vietnamese language, without laboratory practice, it could be really hard to apply these words". All of the thirteen respondents answered "YES" in question 3 of the semi-structured interview (See Appendix E). This can be implied that biology-majored students in Vietnam face obstacles when learning multisyllabic terms because of the monosyllabicity of their mother tongue.

\section{Is there any improvement in students' vocabulary performance} if morphological analysis instructions are introduced?

Results revealed that both the control and experimental group have registered an increase in the respective means with and without intervention. The control group registered a mean difference of 4.38 while the experimental group registered a mean difference of 10.28. Although both results showed a promising improvement, the mean 


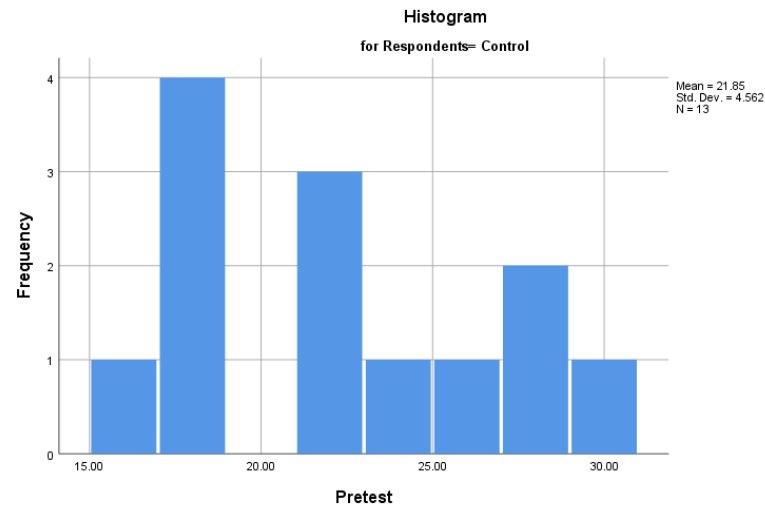

Figure 2 Pretest results of the control group.

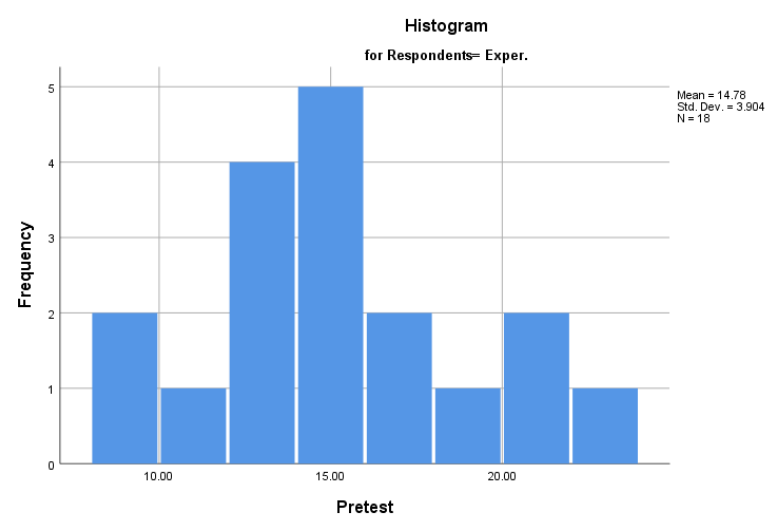

Figure 3 Pretest results of the experimental group.

difference of the experimental group is 5.9 higher than the mean difference of the control group. This can be inferred that the intervention given to the experimental group is more effective than the regular class discussion of the control group. pretest Pretest results revealed that there is a significant difference between the control group and experimental group. The mean difference of the pretest scores between the control and experimental group was found to be 7.07 which is a considerable difference. The comparability of the group was confirmed when an independent samples t-test was done. It was found that the absolute value of the calculated $t$ at $p<0.05$ is bigger than the critical value, which is $4.52>2.045$ (See Appendix A). Statistically, this would mean that the means of the two groups are significantly different which proves the initial assumption that the control group can perform better in the pretest compared to the experimental group because the respondents of the control group are academically advanced and they are exposed to science vocabularies compared to the grade ten respondents of the experimental group. Eight students in the control group scored equal or more than 20 in the pretest which had 40 test items, and only five students scored less than 20. One student scored 30 which is $70 \%$ of the total test items and which is the highest among the 13 respondents. Fifteen students scored below 20 in the pretest, and only three students scored above 20 . This result shows that there is a big gap of the vocabulary level between the control and experimental group. Posttest The posttest scores of the experimental and control group were compared to prove whether or not the experimental group was able to catch up with the level of vocabulary performance of the control group. The t-test result to
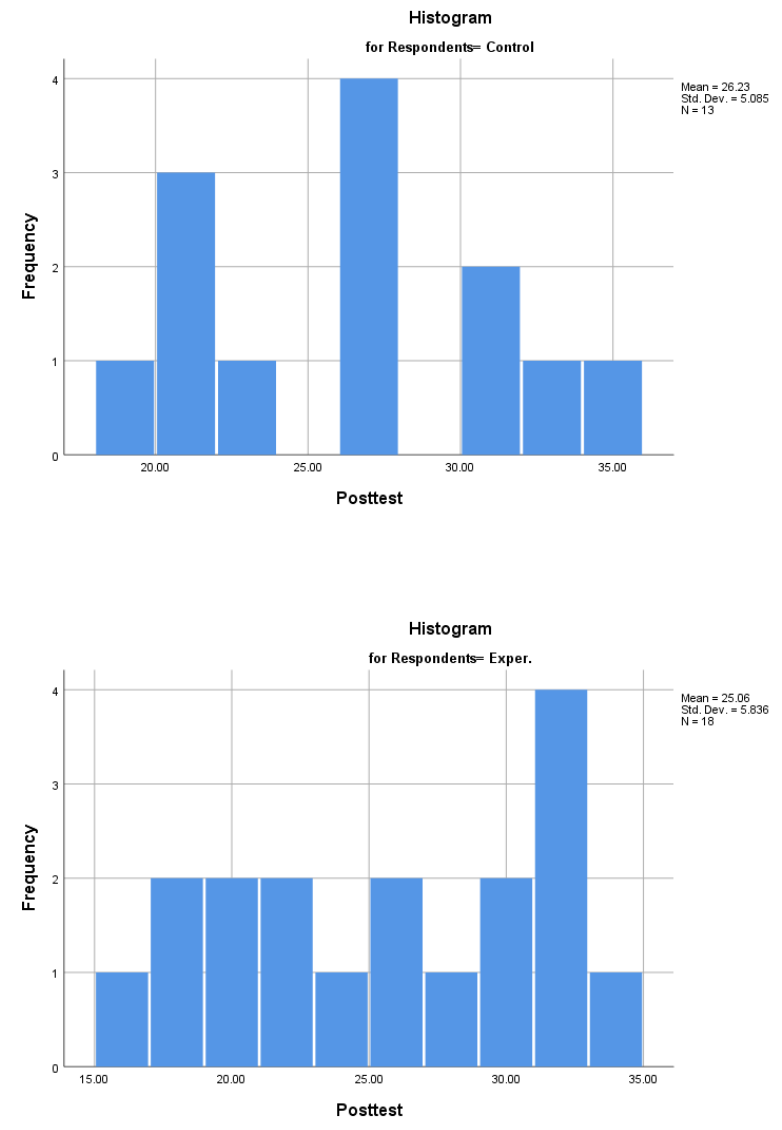

compare the posttest result of the experimental and control group revealed that that at $\mathrm{p}<0.05$, the calculated $\mathrm{t}$ is below the critical value, which is .0596 > 2.045 (See Appendix D). Statistically, the means of the two groups were found significantly similar. This implies that the intervention applied to the experimental group was effective to that point that the ten graders were able to catch up with the level of biotechnology students, in terms of vocabulary performance. The posttest results of the control group show an increase in the mean average up to 4.38. Twelve students scored above 20 and only one scored below. Four students scored above 30 (which is $75 \%$ of the total test items). We can infer that the usual classroom discussion where the instructor used a syllabic based approach is also effective in improving the vocabulary performance of the biotechnology students. The posttest results of the experimental group reveal a remarkable increase in the mean average up to 10.28. Unlike in the pretest where fifteen students scored below 20 and only 3 scored above, alternately, in the posttest only 3 students scored less than 20 and fifteen scored 20 and above, with five students scoring above 30 which is $75 \%$ of the total test item. These results display that the morphological analysis instruction given to the grade 10 biology-majored students was very effective in improving their vocabulary performance to the point that they could keep up with the same pace of those students in biotechnology.

\section{CONCLUSIONS}

In order to effectively comprehend the complex language of science, students and teachers must know the importance of vocabulary. Biology is a field where research fame is encouraged and 
often the unfortunate result is less emphasis on teaching, especially in terms of vocabulary acquisition. Furthermore, biology-majored students face difficulties in learning unfamiliar multisyllabic technical terms. These technical words of science are introduced to students directly without further dissecting and explaining its meaningful fragments. The syllabic-based approach is a good example where students are taught to utter multisyllabic science words without fragmentations of meaningful units. Based on the findings of this study, it was proven that the morphological analysis instruction was effective in enhancing Tan Tao High School's grade-ten biology-majored students' vocabulary performance, to the point that they surpass the performance level of those biotechnology college students. The conclusion above is supported by the data which were analyzed by using IBM SPSS Statistics 26 and Microsoft Excel. Initially, as expected, there was a significant difference in the vocabulary level of the experimental and control group. The comparability of the group was confirmed when an independent samples t-test was done. It was found that the absolute value of the calculated $t$ at $p<0.05$ is bigger than the critical value, which is $4.52>2.045$ (See Appendix A). Statistically, this would mean that the means of the two groups are significantly different which proves the initial assumption that the control group can perform better in the pretest compared to the experimental group However, on the posttest, t-test to compare the posttest result of the experimental and control group revealed that that at $\mathrm{p}<0.05$, the calculated $\mathrm{t}$ is below the critical value, which is $.0596>2.045$ (See Appendix D). Statistically, the means of the two groups were found to be significantly similar. This result proves that through morphological analysis instruction, the grade ten biology-majored students were able to match with the biotechnology students, in terms of vocabulary level. The researcher believes that the findings of this study have some pedagogical implications in teaching technical terms. Attention and effort must be given to students of science because the language of science is intricate and perplexing. Teachers and researchers can work together to apply the strategies, including morphological instruction to help students improve their performance on comprehension, spelling, and vocabulary acquisition

\section{REFERENCES}

[1] Frederick Obniala. Enhancing science vocabulary through active learning approach: Impact to students' performance. Journal of Humanities and Education Development (JHED), 1(3):88-96, May 2019.

[2] Ana Houseal, Victoria Gillis, Mark Helmsing, and Linda Hutchison. Disciplinary literacy through the lens of the next generation science standards. Journal of Adolescent Adult Literacy, 59:377-384, 012016.

[3] Timothy Shanahan and Cynthia Shanahan. What is disciplinary literacy and why does it matter? Topics in Language Disorders, 32:7-18, 012012.

[4] Zhihui Fang. The language demands of science reading in middle school. International Journal of Science Education - INT J SCI EDUC, 28:491-520, 042006.

[5] Tamara M. Green. The Greek E Latin roots of English. Rowman \& Littlefield, Lanham, fifth edition edition, 2015.

[6] Peter Bowers, John Kirby, and Hélène Deacon. Bowers, p. n., kirby, j. r., deacon, s. h. (2010). the effects of morphological instruction on literacy skills: A systematic review of the literature. review of educational research, 80, 144-179. Review of Educational Research, 80:144-179, 012010.

[7] Amanda P. Goodwin and Soyeon Ahn. A meta-analysis of morphological interventions: Effects on literacy achievement of children with literacy difficulties. Annals of Dyslexia, 60(2):183-208, December 2010.

[8] Deborah Reed. A synthesis of morphology interventions and effects on reading outcomes for students in grades k-12. Learning Disabilities Research Practice, 23:36 - 49, 022008.

[9] Michael Green and Nonie Lesaux. Morphing into adolescents: Active word learning for english-language learners and their classmates in middle school. Journal of Adolescent Adult Literacy, 54:47 - 56, 092010.

[10] Dinh Dien, Hoang Kiem, and Nguyen Toan. Vietnamese word segmentation. pages 749-756, 012001.

[11] V.W. Berninger, W.E. Nagy, J. Carlisle, J. Thomson, D. Hoffer, S. Abbott, R. Abbott, T. Richards, E. Aylward, and B.R. Foorman. Effective treatment for children with dyslexia in grades 4-6: Behavioral and brain evidence, symposium, preventing and remediating reading difficulties: bringing science to scale. In Preventing and remediating reading difficulties: bringing science to scale, SYMPOSIUM, Preventing and remediating reading difficulties: bringing science to scale, pages 381-418, Baltimore, 2003. York Press;

[12] Alpana Bhattacharya and Linnea Ehri. Graphosyllabic analysis helps adolescent struggling readers read and spell words. Journal of learning disabilities, 37:331-48, 082004.

[13] Jennifer L. Zoski, Kristin M. Nellenbach, and Karen A. Erickson. Using morphological strategies to help adolescents decode, spell, and comprehend big words in science. Communication Disorders Quarterly, 40(1):57-64, 2018.

[14] lestari setyowati and Sony Sukmawan. Syllabic-based approach for learning to read in bahasa indonesia for early readers. 052018.

[15] Joanne Carlisle and C. Stone. Exploring the role of morphemes in word reading. Reading Research Quarterly - READ RES QUART, 40:428-449, 102005.

[16] John Merrow, John D. Tulenko, Carrie Glasser, John Heus, Shae Isaacs, David Wald, Perry Ryan, Inc. Learning Matters, and PBS Home Video. Declining by degrees : higher education at risk, 2005.

[17] Mohamed Badawi. The effect of explicit english morphology instruction on efl secondary school students' morphological awareness and reading comprehension. English Language Teaching, 12:166, 032019.

[18] Ismalianing Eviyuliwati, Dillan Dzikrika, and Bahrul Hasibuan. The effectiveness of morphological analysis technique in teaching vocabulary. English Language in Focus (ELIF), 1:9, 072019.

[19] Thomas G. White, Michael A. Power, and Sheida White. Morphological analysis: Implications for teaching and understanding vocabulary growth. Reading Research Quarterly, 24(3):283-304, 1989.

[20] Angela N. McLeod and Kenn Apel. Morphological awareness intervention: Study of a child with a history of speech and language impairment. Communication Disorders Quarterly, 36(4):208-218, 2015.

[21] Patrick C. Manyak, James F. Baumann, and Ann-Margaret Manyak. Morphological analysis instruction in the elementary grades: Which morphemes to teach and how to teach them. The Reading Teacher, 72(3):289-300.

[22] Luong Thi Thuan and Ha Kim Phuong. A comparison between english and vietnamese morpheme system. 
t-Test: Two-Sample Assuming Unequal Variances

Comparing means of Pretests at $\mathrm{p}<0.05$

\begin{tabular}{lrr}
\hline & Pretest Control & Pretest Experimental \\
\hline Mean & 21.84615385 & 14.77777778 \\
Variance & 20.80769231 & 15.24183007 \\
Respondents & 13 & 18 \\
df & 29 & \\
t Stat & 4.5518254755 & \\
P $(\mathrm{T}<=)$ two-tail & 0.000154665 & \\
t Critical two-tail & 2.045 & \\
\hline
\end{tabular}

APPENDIX B

t-Test: Two-Sample Assuming Unequal Variances

Means of Control group at $\mathrm{p}<0.05$

\begin{tabular}{lrr}
\hline & Posttest & Pretest \\
\hline Mean & 26.23076923 & 21.84615385 \\
Variance & 25.85897436 & 20.80769231 \\
Respondents & 13 & \\
df & 11 & \\
t Stat & 2.314194137 & \\
$\mathrm{P}(\mathrm{T}<=)$ two-tail & 0.02953309 & \\
t Critical two-tail & 2.201 & \\
\hline
\end{tabular}

t-Test: Two-Sample Assuming Unequal Variances

Means of Experimental group at $p<0.05$

\begin{tabular}{lrr}
\hline & Posttest & Pretest \\
\hline Mean & 25.05555556 & 14.77777778 \\
Variance & 34.05555556 & 15.24183007 \\
Respondents & 18 & \\
df & 16 & \\
t Stat & 6.210456609 & \\
$\mathrm{P}(\mathrm{T}<=)$ two-tail & $7.75384 \mathrm{E}-7$ & \\
t Critical two-tail & 2.12 & \\
\hline
\end{tabular}

\section{APPENDIX D}

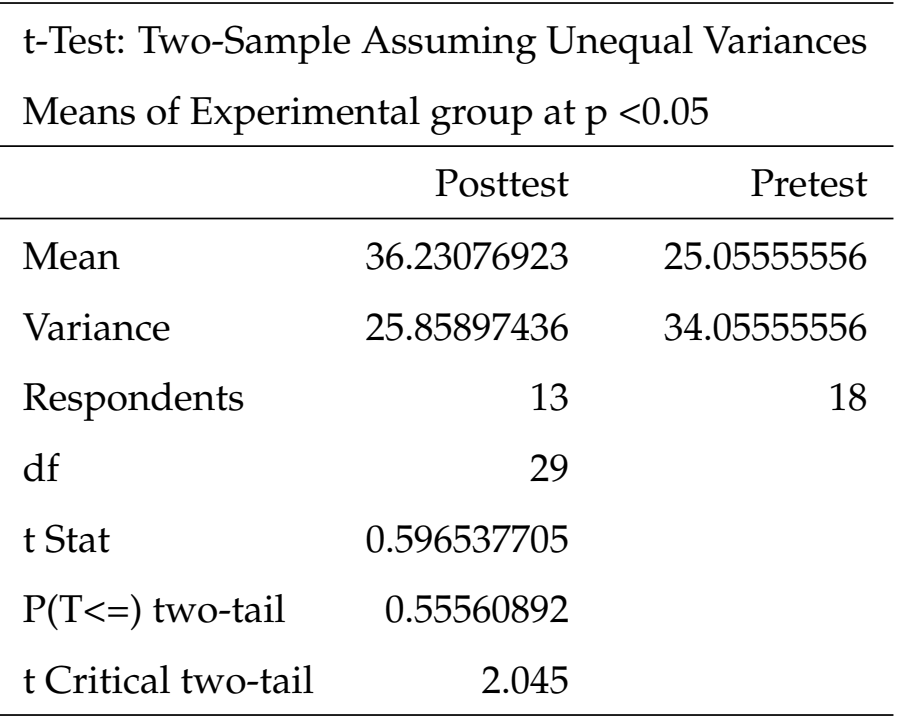

\section{APPENDIX E}

\section{SEMI-STRUCTURED INTERVIEW QUESTIONS SHEET}

Student's name: Date of Interview:

Major: Location:

Year level: Date:

1. What do you like about your major?

2. Do you prefer laboratory practice or theory courses? And Why?

3. As a Vietnamese-native speaker, does your native language affect your learning in Biology? If so, how? 
4. What other challenges do you encounter in acquiring technical vocabulary?

5. Do your teachers fragment words when introducing multisyllabic-technical terms?

6. Does your teacher translate multisyllabic science terms into Vietnamese when teaching biology? 